\title{
Instructors’ Beliefs and Values about Learning Problem Solving
}

\author{
Patricia Heller*, Kenneth Heller*, Charles Henderson*, Vince H. Kuo*, Edit Yerushalmi* \\ *Physics Education Research Group, University of Minnesota, Minneapolis, MN \\ ${ }^{\xi}$ Weizmann Institute, Rehovot, Israel
}

\begin{abstract}
This paper presents preliminary hypotheses about a common core of faculty beliefs about how their students learn to solve problems in their introductory courses. Using a process of structured interviews and a concept map based analysis, we find that faculty appear to believe that students learn problem solving primarily through a process of reflective introspection (educators call this process metacognition) while they practice solving problems and getting assistance from example problem solutions.
\end{abstract}

\section{Introduction}

This paper describes the initial results of a study to determine if there is a common core of physics faculty values and beliefs about the teaching and learning of problem solving. This knowledge could be useful to curriculum developers since materials and curricula congruent with faculty beliefs are more likely to be used by them. We analyzed the interviews, described in the previous paper ${ }^{1}$, of six physics faculty from a research university to generate a hypothesis about their common beliefs and values in this context. As a check of the consistency of the analysis, the resulting concept maps that represent this belief system were examined to determine their overlap with simplified versions of standard instructional theories (e.g. behaviorist, developmental, cognitive apprenticeship) ${ }^{2}$ and compared to a similar analysis of individual statements from the interview. In future work we will map the variations elaborating these common beliefs, compare these instructors' teaching beliefs to their learning beliefs, and test the generality of the hypotheses generated by this analysis procedure using additional physics faculty interviews described in the previous paper ${ }^{1}$.

\section{Data sample}

We began with an in-depth analysis of the interview data of six physics faculty from the same research university because the structure of their introductory physics course and the nature of their students have been documented by us. We can check the consistency of the interview data with reality. These instructors each lecture to a class of about 200 students in a calculusbased introductory physics course. The students also participate in laboratories and recitation sections taught by graduate teaching assistants using the structure of cooperative group problem solving ${ }^{3,4}$. Each faculty member meets with his or her TAs at least once per week while teaching the course. Continuous testing by our group has shown that the students in these courses show adequate achievement gains in both concept development and problem solving. For example, they show an average Hake gain of about 0.4 on the FCI with a pretest of about $50 \%$, with little variation from instructor to instructor ${ }^{5,6}$. The lectures of the faculty have been observed to be very similar to those given in more traditional formats, but the context in which they are teaching (student recitation sections and laboratories) is influenced by the cognitive apprenticeship instructional paradigm ${ }^{7}$. Although all of these faculty are active in traditional physics research and have no direct experience with physics education research, the department in which they teach has a physics education research group giving them some exposure to issues in physics education. Since all of these instructors teach similar students under the same instructional structure at the same 
institution, we expected that this sample is the most likely to show a common core of beliefs about the teaching and learning of problem solving if such a core exists, and if our interview instrument and analysis is sensitive to it.

\section{Analysis Technique}

Each interview was transcribed, yielding six transcripts each of about 30 pages. Where transcripts were unclear, we referred back to the original videotapes of the interview. The analysis process used these transcripts to develop a multi-layered concept map representing the values and beliefs of each faculty member with respect to the student learning of physics problem solving.

Data analysis started with the final stages of the interview, in which the interviewer asked a series of questions to elicit responses about student and teacher actions

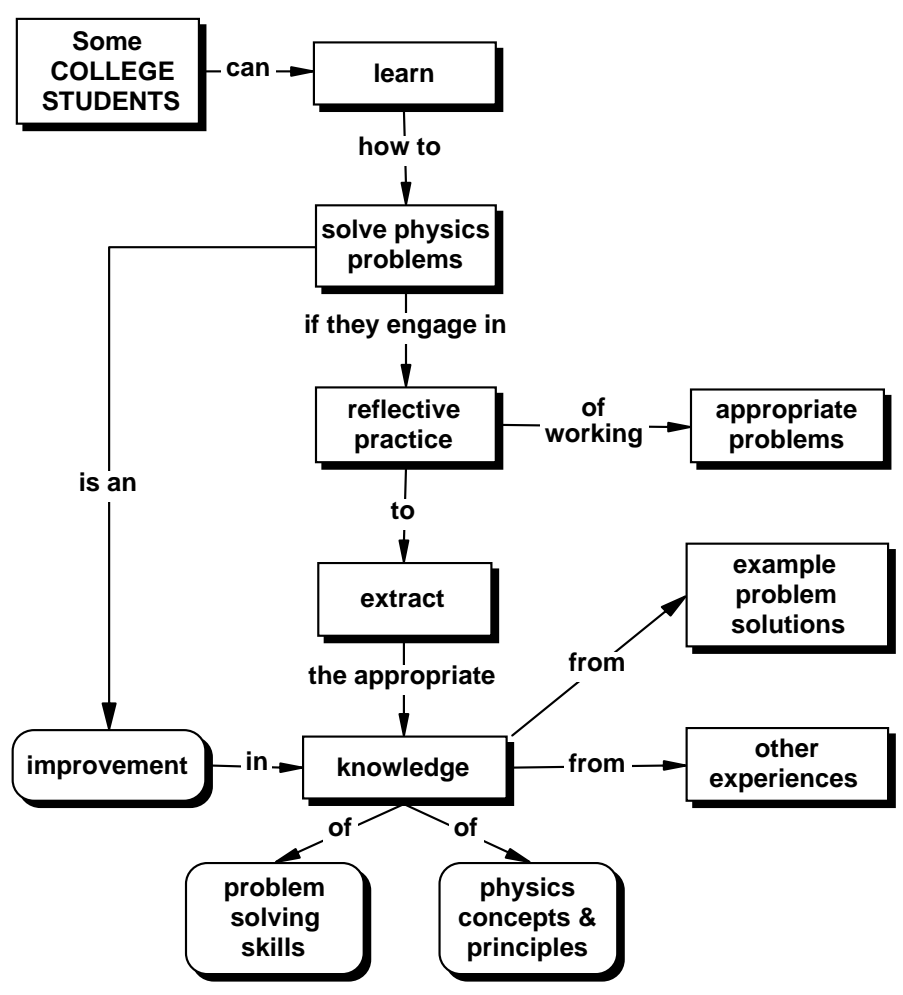

Figure 1: Concept map of faculty beliefs and values about student learning of problem solving in an introductory physics course. helpful for students to improve their problem solving skills. Standard concept mapping procedures were used to make a preliminary map of faculty beliefs. The previous parts of the interview were then examined to either confirm or refute elements of the map. In the course of this process, new features of the map might be uncovered or postulated features eliminated or reorganized. This process yielded results that indicate an organized intellectual framework of beliefs about student learning. A single map could be constructed to represent all six professors.

\section{Preliminary Results}

The preliminary hypothesis of the faculty view of learning problem solving is shown in Figure 1. Each of the boxes on the map was further elaborated to specify its meaning for these instructors. For example, the map of "some college students" is shown in Figure 2.

Figure 1 indicates that these instructors believe their students learn problem solving primarily through a process we call reflective practice. The following statement from the transcripts illustrates this concept: "you look at problems not to go through the problem and compare your answer. But instead you have to discipline yourself to say exactly what was the reason I wrote this particular line of algebra down." They also believe that solving physics problems both requires conceptual knowledge and helps to increase it. The instructors recognize that practice solving problems and getting assistance must be accompanied by a process of introspection that educators call metacognition. Figure 2 shows that faculty target the majority of the students who they perceive as average, but believe that only a fraction of those have the 
motivation to apply reflective practice.

The reflective learning-by-doing process is believed to be idiosyncratic and cannot be reduced to a common procedure. This view has features in common with the cognitive apprenticeship outlook on learning, but it lacks the recognition of general-purpose heuristics necessary for developing expertise in problem solving. The interview data revealed the belief that the skills necessary for reflective practice might be both a prerequisite to learning to solve problems in the introductory course, and a long-term goal of the university educational process that is unachievable in a single year. This potential instructional paradox is described in the next paper ${ }^{8}$.

\section{Checking the Map}

As a simple test of the apprenticeship nature of the common belief structure resulting from our concept map analysis, we sorted the statements that faculty made during the

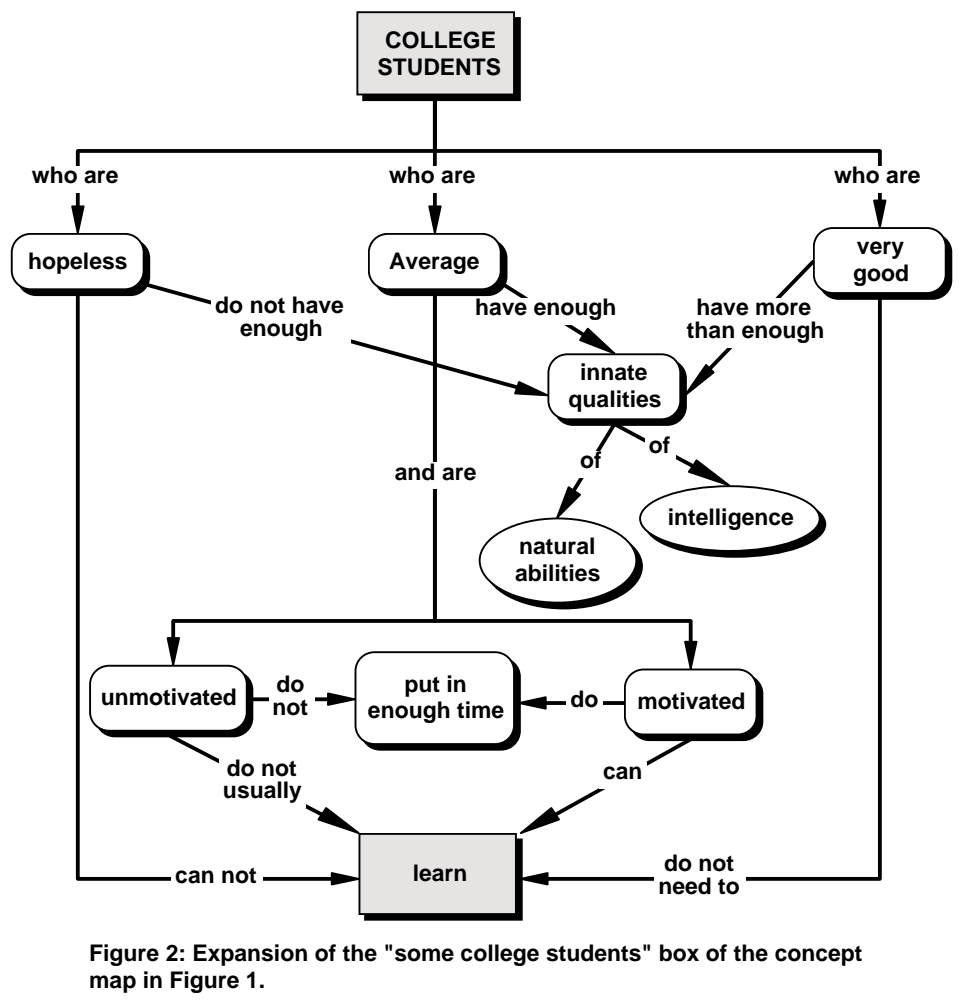

entire interview according to their similarity to features of the standard instructional paradigms of behaviorist, developmental, and cognitive apprenticeship ${ }^{2}$. Each statement about the teaching or learning of problem solving was categorized as being consistent with one of these instructional paradigms if it was evident. If the statement was judged to be ambiguous, it was either classified as clearly opposed to one of the paradigms while not distinguishing between the other two, or as unclassifiable. This classification was performed independently for each statement in each interview by two of the authors. There was good agreement among the six faculty members in the sample. The result of this check, given in Figure 3, was consistent with the concept map analysis.

As can be seen from the graph, these faculty hold beliefs about the student learning of problem solving that are most consistent with apprenticeship and least consistent with behaviorist paradigms. Whether this reflects a more general set of faculty beliefs or simply the environment in which these six professors teach will be tested by performing the same analysis on the other 24 interviews. This simple counting result is consistent with the qualitative concept map analysis that shows the instructors believe that students learn problem solving by a complex process of practice that is characteristic of apprenticeship. They show no evidence of believing that problem solving can be learned by the incremental practice of component skills.

\section{Discussion}

The interview technique based on specific artifacts seems to 


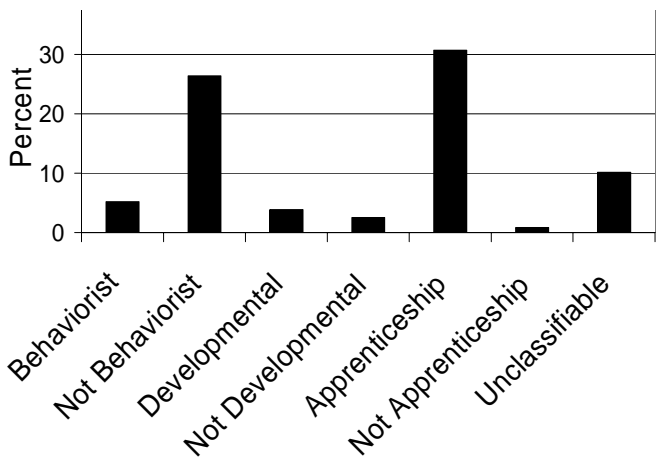

Figure 3: Average percentage of statements on student learning classified as being consistent with standard instructional paradigms.

yield consistent results for instructor beliefs and values with respect to student learning of problem solving for a small sample of faculty from a single institution. With our limited information, we can generate a hypothesis that is testable using further interviews and questionnaire techniques in the more general population. If our initial small sample is any indication of the general physics faculty population, there will be some lessons for the curriculum developer. A hypothesis based on this preliminary data would be that the natural inclination of faculty favors apprenticeship approaches to problem solving and opposes the incremental learning that characterizes behaviorism. However, there appears to be no appreciation of the need of scaffolding that is part of a cognitive apprenticeship paradigm. A natural "language" sympathetic to developmental approaches does not seem to exist to any great extent. These instructors have well-developed ideas of how students should learn problem solving but, as discussed in the next paper ${ }^{8}$, their teaching goals are not closely matched to these ideas.

${ }^{1}$ Kuo, V.H., Heller, K., Heller, P., Henderson, C., \& Yerushalmi, E., Instructor's Ideas about Problem Solving - Grading. Proceedings of Physics Education Research Conference, Rochester, NY, July, 2001.
${ }^{2}$ Farnham-Diggory, S., Paradigms of Knowledge and Instruction, Review of Educational Research, vol. 64, p. 463, 1994. Brief and incomplete definitions: Behaviorist - The important difference between expert and novice is the amount of knowledge. The mode of instruction is to incrementally add knowledge to the learner. The teacher provides the knowledge broken down into its essential components.

Developmental - The important difference between expert and novice is the usefulness of their thinking framework to organize knowledge. Each framework must be developed in a sequentially so that a new framework replaces the old. The mode of instruction is destroying the existing framework and building a new framework. The teacher provides a series of activities to contradict expectations based on the old framework followed by those to evoke a new one.

Cognitive Apprenticeship - The important difference between an expert and a novice is the organization of the interconnections among knowledge. The interconnections depend on previous experiences and differ from individual to individual. The mode of instruction is building upon and reorganizing mental interconnections in a context meaningful to the learner. The teacher shows what is expected within a context relevant to the learner's experiences (modeling). The learner practices a similar task with assistance (coaching). This coaching can consist of structuring the task (scaffolding). Help is slowly removed so that the learner accomplishes similar tasks (fading).

${ }^{3}$ Heller, P., Keith, R., \& Anderson, S., Teaching problem solving through cooperative grouping. Part 1: Groups versus individual problem solving, American Journal of Physics, vol. 60, p. 627, 1992. ${ }^{4}$ Heller, P., \& Hollabaugh, M., Teaching problem solving through cooperative grouping. Part 2: Designing problems and structuring groups, American Journal of Physics, vol. 60, p. 637, 1992.

${ }^{5}$ Hestenes, D., Wells, M., Swackhamer, G., Force Concept Inventory, The Physics Teacher, vol. 30, p. $141,1992$.

${ }^{6}$ Hake, R., Interactive-engagement vs. traditional methods: A six-thousand-student survey of mechanics test data for introductory physics courses, American Journal of Physics, vol. 66, p. 64, 1998.

${ }^{7}$ Collins, A., Brown, J., \& Newman, S., Cognitive apprenticeship: Teaching the craft of reading, writing, and mathematics, in Resnick, L. (ed.), Knowing, Learning, and Instruction: Essays in Honor of Robert Glaser, Erlbaum, 1989.

${ }^{8}$ Henderson, C., Heller, K., Heller, P., Kuo, V.H., \& Yerushalmi, E., Instructor's Ideas about Problem Solving - Grading. Proceedings of Physics Education Research Conference, Rochester, NY, July, 2001. 